\title{
$\mu$-Nitrido Bridged Diiron Phthalocyanines: Old Complexes for New Catalytic Applications
}

\author{
Evgeny V. Kudrik, ${ }^{\mathrm{a}, \mathrm{b}}$ and Alexander B. Sorokin ${ }^{\mathrm{a}}$ \\ Dedicated to Professor Claudio Ercolani on the occasion of his $75^{\text {th }}$ birthday
}

a'Institut de Recherches sur la Catalyse et l'Environnement de Lyon (IRCELYON), UMR 5256, CNRS-Université Lyon 1, 2 av. A. Einstein, 69626 Villeurbanne Cedex, France

${ }^{\mathrm{b}}$ Ivanovo State University of Chemistry and Technology, 153000 Ivanovo, Russia

@Corresponding author E-mail: alexander.sorokin@ircelyon.univ-lyon1.fr

\begin{abstract}
Binuclear N-bridged M-N-M (M=transition metal) complexes on phthalocyanine platform constitute an emerging class of oxidation catalysts. Their unusual structure provides unprecedented catalytic properties and reactivity. The most significant so far example is the mild oxidation of methane. In addition to oxidation of strong $\mathrm{C}-\mathrm{H}$ bonds in alkanes, aromatic and alkylaromatic compounds $\mu$-nitrido diiron phthalocyanines catalyze the formation of $C$-C bonds exemplified by hydroacylation of olefins with aldehydes. A clean and practical character of this system coupled with real availability of the phthalocyanines suggests a high application potential of this approach. This system has a great potential for further development by modification of the structure.
\end{abstract}

Keywords: Iron phthalocyanine, $\mu$-nitrido dimer, methane, catalysis, oxidation.

\section{Introduction}

The first $\mu$-nitrido diiron phthalocyanine was prepared and characterized by C. Ercolani and co-workers in $1984 .{ }^{[1]}$ This complex was prepared from unsubstituted $\mathrm{FePc}$ and sodium azide by heating at high temperature in 1-chloronaphthalene. Together with synthesis of $\mu$-nitrido diiron tetraphenylporphyrin ${ }^{[2]}$ this study has initiated a novel research direction devoted to these interesting complexes with $-\mathrm{N}=\mathrm{M}(\mathrm{M}=\mathrm{Fe}, \mathrm{Mn}, \mathrm{Ru})$ structural motif in macrocyclic ligand environment. Since then, this area has been largely developed due to the works by Ercolani's group ${ }^{[3-9]}$ Porphyrin and phthalocyanine macrocyclic ligands in homoleptic and heteroleptic arrangements have been used to accommodate $\mathrm{M}-\mathrm{N}=\mathrm{M}$ structural unit with the same and different transition metals in a variety of combinations. ${ }^{[10-14]} \mu$-Nitrido dimers based on non-macrocyclic ligands have been also described. ${ }^{[15]}$ A progress in the synthesis and characterization of these systems has nicely been reviewed by Ercolani et al. ${ }^{[16]}$

An important property of these complexes is the very high stability of dimeric construction provided by bridging nitrogen atom which is strongly bonded as indicated by X-ray photoelectron spectroscopy (XPS) data. The 1s N XPS spectrum of $\left(\mathrm{FePc}^{t} \mathrm{Bu}_{4}\right)_{2} \mathrm{~N}$ along with strong signal at 398.7 $\mathrm{eV}$ from nitrogen atoms of phthalocyanine moieties exhibits a small signal at $402.4 \mathrm{eV}$ which can be assigned to strongly bonded $\mu$-bridging nitrogen atom. ${ }^{[17]}$ This strong bonding explains the high stability of $\mu$-nitrido bridged species. Electrospray ionization mass-spectrometry (ESI-MS) data also indicate the high stability of dimeric structure. ESI-MS spectrum of $\left(\mathrm{FePc}^{t} \mathrm{Bu}_{4}\right)_{2} \mathrm{~N}$ exhibits a strong molecular peak at $m / z=1599.8$ with no fragmentation due to monomerization. $(\mathrm{FePc})_{2} \mathrm{~N}$ complex can be considered as bimetallic mixed valence $\mathrm{Fe}^{\mathrm{III}}-\mathrm{N}-\mathrm{Fe}^{\mathrm{IV}}$ system with one delocalized unpaired electron as evidenced from Mössbauer and EPR data. ${ }^{[3]}$ Mössbauer spectrum contains only one single doublet with $\delta$ $=0.06 \mathrm{~mm} \cdot \mathrm{s}^{-1}$ and $\Delta E_{\mathrm{O}}=1.76-1.78 \mathrm{~mm} \cdot \mathrm{s}^{-1}$ indicative of two equivalent iron sites with intermediate +3.5 oxidation state. Selected Mössbauer data for $\mu$-nitrido bridged complexes are listed in Table 1.

The room temperature magnetic moment for this dimer $\left(2.13 \mu_{\mathrm{B}}\right)$ also shows the presence of one unpaired electron

Table 1. Selected Mossbauer data for $\mu$-nitrido bridged complexes.

\begin{tabular}{ccccc}
\hline Complex & $\delta, \mathrm{mm} \cdot \mathrm{s}^{-1}$ & $\Delta E_{\mathrm{Q}}, \mathrm{mm} \cdot \mathrm{s}^{-1}$ & $\Gamma, \mathrm{mm} \cdot \mathrm{s}^{-1}$ & Ref. \\
\hline$(\mathrm{TPPFe})_{2} \mathrm{~N}$ & 0.148 & 1.07 & 0.44 & 2 \\
$(\mathrm{PcFe})_{2} \mathrm{~N}$ & 0.06 & 1.76 & 0.19 & 3 \\
$(\mathrm{TPPMn}) \mathrm{N}(\mathrm{FePc})$ & 0.19 & 1.21 & 0.13 & 8 \\
$(\mathrm{TPPFe}) \mathrm{N}(\mathrm{FePc})$ & 0.11 & 1.47 & 0.19 & 6 \\
$(\mathrm{TPPFe}) \mathrm{N}(\mathrm{RuPc})$ & 0.03 & 0.90 & 0.22 & 7 \\
$(\mathrm{TPPFe}) \mathrm{N}(\mathrm{RuPc})^{-+}$ & -0.01 & 1.85 & & 7 \\
\hline
\end{tabular}


per molecule. ${ }^{[4]}$ These data together with EPR parameters of $(\mathrm{PcFe})_{2} \mathrm{~N}$ with typical axial symmetric structure $\left(\mathrm{g}_{\|}=\right.$ 2.03 and $\mathrm{g}_{\perp}=2.13$ ) can be assigned to low-spin ground state of iron sites. In contrast to corresponding monomeric and $\mu$-oxo-dimeric iron phthalocyanines, $(\mathrm{PcFe})_{2} \mathrm{~N}$ doesn't form stable adducts with strong nitrogen bases, like pyridine and is not reduced to $\mathrm{Fe}^{\mathrm{II}}$ monomeric species, $\mathrm{PcFe}(\mathrm{Py})_{2}$. $(\mathrm{PcFe})_{2} \mathrm{~N}$ can be easily oxidized by ferrocenium cation to give $\left(\mathrm{PcFe}^{\mathrm{IV}}\right)_{2} \mathrm{~N}^{+}$. Its Mössbauer spectrum shows a clean doublet with a negative isomer shift of $-0.10 \mathrm{~mm} \cdot \mathrm{s}^{-1} \cdot{ }^{[4]}$

The similar approach was used for the synthesis of $(\mathrm{PcRu})_{2} \mathrm{~N}$ complex. Heating of $\mathrm{PcRuPy}_{2}$ with an excess of sodium azide in boiling 1-chloronaphthalene gave $\mu$-nitrido bridged diruthenium complex. ${ }^{[5]} \mathrm{EPR}$ and magnetic measurements indicated that this complex contained one unpaired electron per dimer molecule. X-ray powder pattern showed that this complex was isomorphic with the diiron analogue and could be identified as mixed-valence $\mathrm{Ru}^{\mathrm{III}}-\mathrm{N}$ $\mathrm{Ru}^{\mathrm{IV}}$ dimer.

Ercolani's group has also prepared and investigated different types of $\mu$-nitrido bridged complexes including the systems with same metal but different ligands, (TPP) $\mathrm{FeNFe}(\mathrm{Pc}),{ }^{[6]}$ and with different ligands and metals, (TPP) $\mathrm{FeNRu}(\mathrm{Pc})^{[7]}$ and (TPP)MnNFe(Pc). ${ }^{[8,9]}$ These compounds were synthesised using corresponding metalloporphyrin azido complex and iron phthalocyanine in the controlled conditions. From Mössbauer and EPR data it was concluded that the (TPP)FeNFe(Pc) complex underwent a rapid electronic exchange across the bridging nitrogen atom and both metal centres have intermediate oxidation state +3.5 in spite of asymmetric ligand environment. This is in contrast with behaviour observed for Fe-Ru and Fe-Mn analogues in which the two metal centers showed distinct oxidation states and the complexes were formulated as (TPP)Fe ${ }^{\mathrm{IV}} \mathrm{NRu}^{\mathrm{III}}(\mathrm{Pc})$ and $(\mathrm{Pc}) \mathrm{Fe}^{\mathrm{III}} \mathrm{NMn}^{\mathrm{IV}}(\mathrm{TPP})$, respectively. In the latter complex, the Mössbauer spectrum contained one doublet with isomeric shift of $+0.19 \mathrm{~mm} \cdot \mathrm{s}^{-1}$. This value was significantly higher than those observed for the symmerical $\mu$-nitrido diiron species and was compatible with +3 iron oxidation state rather than with +3.5 one. EPR data were in agreement with this conclusion.

As can be seen from the short historical survey, the $\mu$-nitrido bimetallic macrocyclic complexes exhibit very interesting physico-chemical properties. However, before our work, they have never been evoked as the catalysts for the oxidation or other reactions. It is quite surprising because $\mathrm{we}^{[18-23]}$ and others ${ }^{[23-27]}$ demonstrated promising catalytic properties of $\mu$-oxo diiron phthalocyanines in oxidation. It should be noted that $\mu$-nitrido dimers with unsubstituted phthalocyanine ligands are practically insoluble in most organic solvents and only poorly soluble in 1-chloronaphthalene or pyridine. To access to the complexes soluble in common solvents in order to readily purify, to study and to apply them in catalysis we have synthesized the $\mu$-nitrido diiron phthalocyanine 1 with eight bulky tert-butyl groups (Figure 1).

The synthesis of $\mathbf{1}$ was realised according to the protocol described for $(\mathrm{FePc})_{2} \mathrm{~N}^{\left[{ }^{[28]}\right.}$ This compound can be easily purified by column chromatography on basic alumina. In order to enlarge the choice of the soluble $\mu$-nitrido diiron phthalocyanines we have prepared the complexes 2a-2f

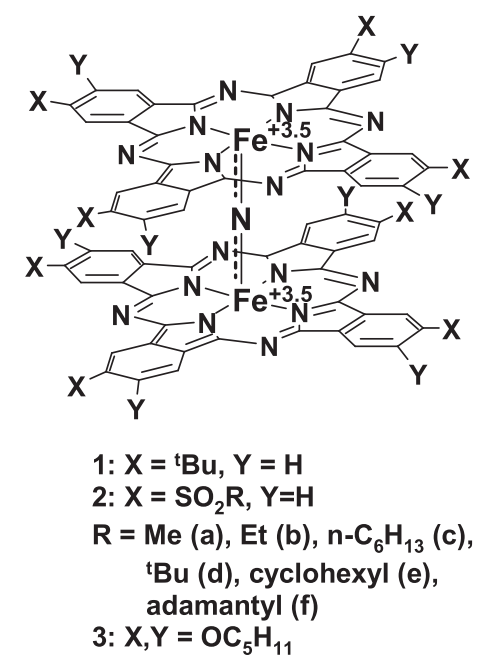

Figure 1. Structures of substituted $\mu$-nitrido diiron phthalocyanines. For tetrasubstituted derivatives only one position isomer is depicted.

containing electron-withdrawing alkylsulfonyl groups. ${ }^{[29-30]}$ An electron-rich $\mu$-nitrido diiron 2,3,9,10,16,17,23,24-octa ( $n$-pentoxy)phthalocyanine complex $\mathbf{3}$ has also been repared. ${ }^{[31]}$ These complexes have been investigated using different spectroscopic techniques (UV-Vis, IR, EPR, Mössbauer, EXAFS, XANES). The introduction of substitients on the periphery of phthalocyanine ring influences on the spectroscopic properties and geometry of these compounds. Nevertheless, the most interesting feature of $\mu$-nitrido diiron phthalocyanines is their remarkable catalytic properties. Although traditional iron phthalocyanine complexes are known to be the versatile catalysts for the selective oxidation and bleaching reactions ${ }^{[32]} \mu$-nitrido diiron counterparts exhibit unprecedented activity in the oxidation of difficultto-oxidize substrates. Below we summarize our recent results on the new applications of these old complexes in catalysis.

\section{Catalytic Applications}

\section{Activation of $\mathrm{H}_{2} \mathrm{O}_{2}$ and Formation of Active Species}

Activation of the oxidant to form oxidizing species is a prerequisite of the oxidative catalytic activity. Addition of hydrogen peroxide to the solution of $\mathbf{1}$ resulted in small but distinctive changes in the UV-Vis spectra. ${ }^{[33]}$ Kinetics of the reaction was investigated under pseudo-first order conditions. The dependence of $k_{\text {obs }}$ vs. $\left[\mathrm{H}_{2} \mathrm{O}_{2}\right]$ exhibited saturation behaviour and can be linearized in LineweaverBurk coordinates. The saturation kinetics suggests a twostep process involving fast reversible binding of $\mathrm{H}_{2} \mathrm{O}_{2}$ to iron followed by slow formation of hydroperoxo diiron complex which was detected using EPR spectroscopy. The formation of $\mathbf{1 - H _ { 2 }} \mathrm{O}_{2}$ adduct in the presence of the $\mathrm{Et}_{3} \mathrm{~N}$ base was evidenced by cryospray mass-spectrometry. ${ }^{[33]}$ Along with signals of $\mathbf{1}^{+}$and $\left(\mathbf{1}_{-}-\mathbf{H}_{\mathbf{2}} \mathbf{O}_{\mathbf{2}}\right)^{+}$at $\mathrm{m} / \mathrm{z}=1599.7268$ and $\mathrm{m} / \mathrm{z}=$ 1633.7322, respectively, a new signal at $\mathrm{m} / z=1615.7239$ corresponding to $(\mathbf{1}+\mathbf{O})^{+}$formulation was observed. On the basis of the spectroscopic data we have proposed the formation of $(\mathrm{Pc}) \mathrm{Fe}^{\mathrm{IV}}-\mathrm{N}-\mathrm{Fe}^{\mathrm{IV}}=\mathrm{O}\left(\mathrm{Pc}^{+}\right)$phthalocyanine 


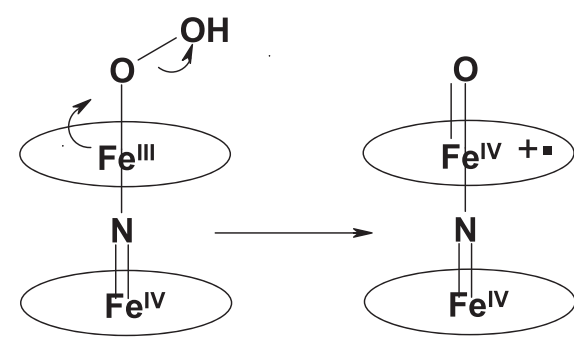

Ultra high-valent diiron oxo species

Figure 2. Proposed mechanism of the formation of diiron oxo species.

cation-radical active species via heterolytic cleavage of $\mathrm{O}-\mathrm{O}$ bond of hydroperoxo (Pc)Fe $\mathrm{Fe}^{\mathrm{IV}}=\mathrm{N}-\mathrm{Fe}^{\mathrm{III}}-\mathrm{OOH}(\mathrm{Pc})$ complex (Figure 2).

Such an oxo species having two $\mathrm{Fe}^{\mathrm{IV}}$ atoms tightly connected by $\mu$-nitrido link and situated in electron-deficient ligand environment should be a very strong short-living oxidant. Indeed, all our efforts to prepare and to characterize it at very low temperature $\left(-80^{\circ} \mathrm{C}\right)$ were unsuccessful. However, we were able to obtain the product of its one electron reduction in solid state with $\mathrm{ca} .70 \%$ yield which was assigned as $(\mathrm{Pc}) \mathrm{Fe}^{\mathrm{IV}}=\mathrm{N}-\mathrm{Fe}^{\mathrm{IV}}-\mathrm{OH}(\mathrm{Pc})$ on the basis of Mössbauer, EPR, XANES and EXAFS spectroscopic data. Another distinctive feature of $\mu$-nitrido diiron phthalocyanine construction is a rather high stability to monomerization and to oxidative destruction in the strong oxidative conditions which is an important requirement for the development of an oxidation catalyst. For example, the half life times of the complex 1 in the presence of 1000 equiv. of hydrogen peroxide were $\tau_{1 / 2}=3470 \mathrm{~min}$ at $25^{\circ} \mathrm{C}$ and $\tau_{1 / 2}=560 \mathrm{~min}$ at $60^{\circ} \mathrm{C}$.

\section{Oxidation of Methane}

We investigated the catalytic properties of $\mathbf{1}$ in the oxidation of different substrates including benzene and methane whose oxidation at mild conditions is considered as one of the most difficult reactions in catalysis. Indeed, the first results indicated very powerful oxidizing ability of $1-\mathrm{H}_{2} \mathrm{O}_{2}$ system. ${ }^{[28]}$ The initial experiments on homogeneous methane oxidation were performed in $\mathrm{CH}_{3} \mathrm{CN}$ at $40^{\circ} \mathrm{C}$ :

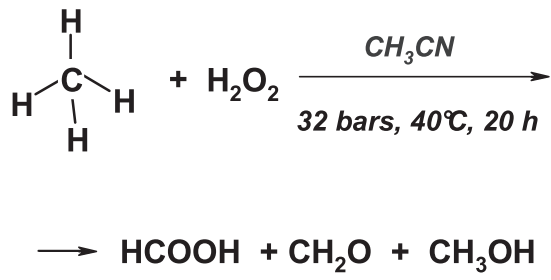

GC-MS analyses of the final reaction mixture showed the presence of formic acid as the principal product and traces of methanol, acetic acid and acetone. $\mathrm{CH}_{2} \mathrm{O}$ was also determined by Nash method. One general important point should be addressed as for the origin of the products of methane oxidation when organic solvents (acetonitrile, acetone, ethanol etc.) are used. The catalytic system could be capable of oxidizing the organic solvent which concentration is much higher than that of methane. Since the products of the oxidation of $\mathrm{MeCN}$ or other organic solvents might be the same as products of oxidation of methane they can be claimed as the products of $\mathrm{CH}_{4}$ oxidation. This problem has not been discussed in many papers devoted to the oxidation of $\mathrm{CH}_{4}$ in organic solvents. However, a careful control of the experiments is necessary in order to determine the origin of oxidation products and to confirm the occurrence of methane oxidation. The control experiment can be performed by using a deuterated solvent. For example, if the oxidation of $\mathrm{CH}_{4}$ is performed in $\mathrm{CD}_{3} \mathrm{CN}$, the products issued from $\mathrm{CH}_{4}$ will contain $\mathrm{H}$ atoms and the products of solvent oxidation will be deuterated. By performing the reaction in $\mathrm{CD}_{3} \mathrm{CN}$ we found that $68 \%$ of products derived from oxidation of $\mathrm{CH}_{4}$ and $32 \%$ of products were originated from the oxidation of acetonitrile (ratio 2:1). A kinetic analysis indicated that this ratio was not compatible with involvement of $\mathrm{OH}^{*}$ radicals. In the latter case this ratio should be $1: 2880 .{ }^{[28]}$

In order to avoid uncertainty owing to the oxidation of organic solvent the most simple and efficient way is to use water as the inert medium. Since $\left(\mathrm{FePc}^{t} \mathrm{Bu}_{4}\right)_{2} \mathrm{~N}$ is insoluble in water, it was supported onto amorphous silica and heterogeneous oxidation of methane was successfully carried out in pure water. The further unambiguous evidence for the oxidation of methane was obtained using labeled ${ }^{13} \mathrm{CH}_{4}$ in about 1:1 mixture with $\mathrm{CH}_{4} \cdot{ }^{13} \mathrm{C}$ NMR analysis of the reaction mixture showed the presence of signals at 81.6 and $165.5 \mathrm{ppm}$ attributed to hydrated formaldehyde ${ }^{13} \mathrm{CH}_{2}(\mathrm{OH})_{2}$ and formic acid $\mathrm{H}^{13} \mathrm{COOH}$, respectively (Figure 3).

No signal at $49 \mathrm{ppm}$ due to ${ }^{13} \mathrm{CH}_{3} \mathrm{OH}$ was found in the ${ }^{13} \mathrm{C}$ NMR spectrum but a small amount of methanol was detected by more sensitive GC-MS method. Importantly, the isotopic compositions of methanol and formic acid reflected the isotopic composition of methane. However, acetic acid and acetone didn't contain ${ }^{13} \mathrm{C}$ label indicating that these products were not produced from $\mathrm{CH}_{4}$ oxidation. Most likely, they originated from the partial degradation of the catalyst. This example illustrates the importance of control experiments, in particular, using labelling method.

On the basis of spectroscopic, reactivity and labelling data one can conclude that $\mathrm{H}_{2} \mathrm{O}_{2}$ reacts with the complex 1 with formation of a high valent diiron oxo-complex and oxidation of methane takes place via oxo-chemistry rather than radical pathway. The tentative reaction mechanism is proposed Figure 4.

The study of temperature dependence of the heterogeneous oxidation of methane showed that catalytic reaction took place even at $25^{\circ} \mathrm{C}$ in pure water though with a moderate turnover number of 13 . The catalytic system was more active at $40-80^{\circ} \mathrm{C}$ providing $\mathrm{TON} \sim 26-29 .{ }^{[28,34]}$

\section{Improvement of Methane Oxidation and Oxidation of Ethylene and Propane}

According to the proposed mechanism (Figure 4), the active oxo species is formed from hydroperoxo complex $\mathrm{Fe}^{\mathrm{IV}}=\mathrm{N}-\mathrm{Fe}^{\mathrm{III}}-\mathrm{OOH}$ via heterolytic cleavage of $\mathrm{O}-\mathrm{O}$ bond. A protonation of peroxide oxygen should favour the $\mathrm{O}-\mathrm{O}$ cleavage because water is a better leaving group than hydroxide anion. Consequently, we have performed the oxidation of methane in very diluted $\mathrm{H}_{2} \mathrm{SO}_{4}$ solutions. Indeed, 


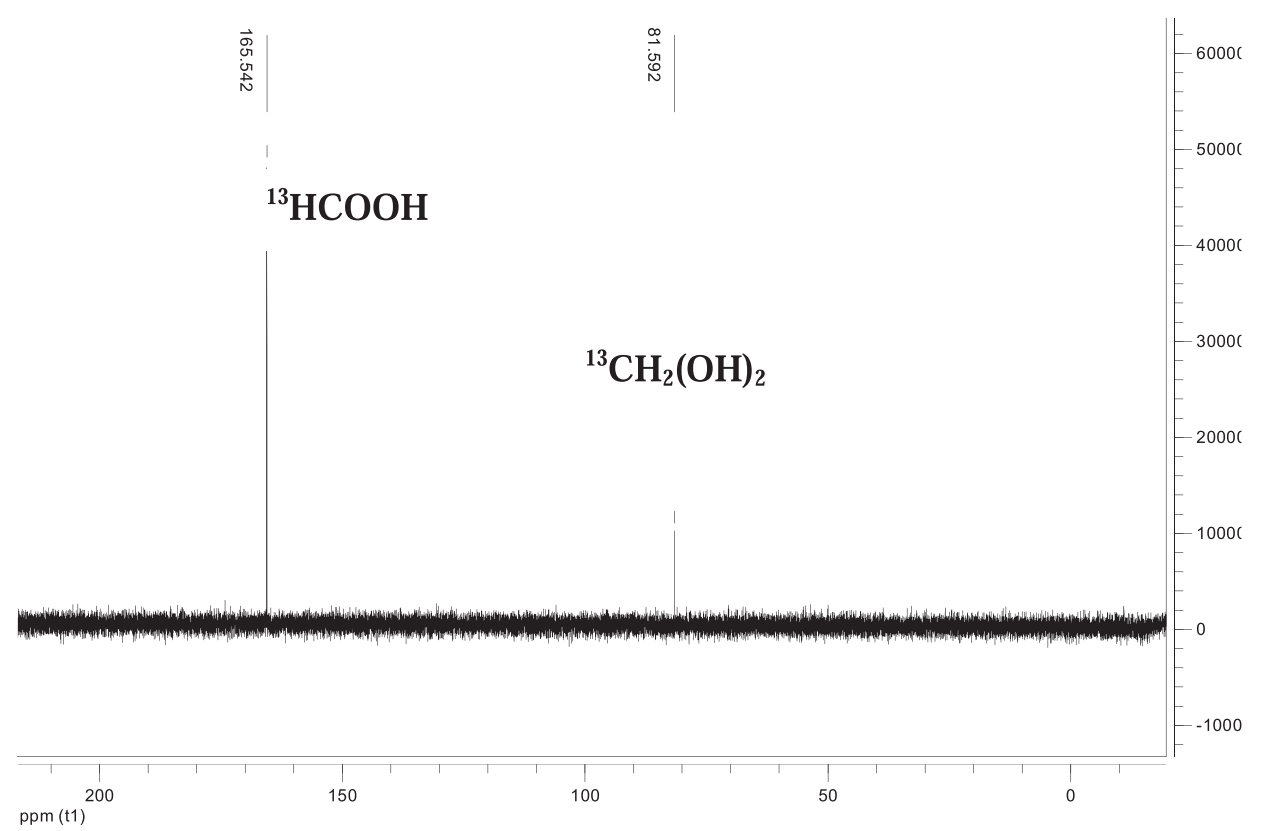

Figure 3. ${ }^{13} \mathrm{C}$ NMR spectrum of the crude aqueous solution from the oxidation of the ${ }^{13} \mathrm{CH}_{4}$ and $\mathrm{CH}_{4}$ in $\mathrm{D}_{2} \mathrm{O}$ at $60^{\circ} \mathrm{C}$.

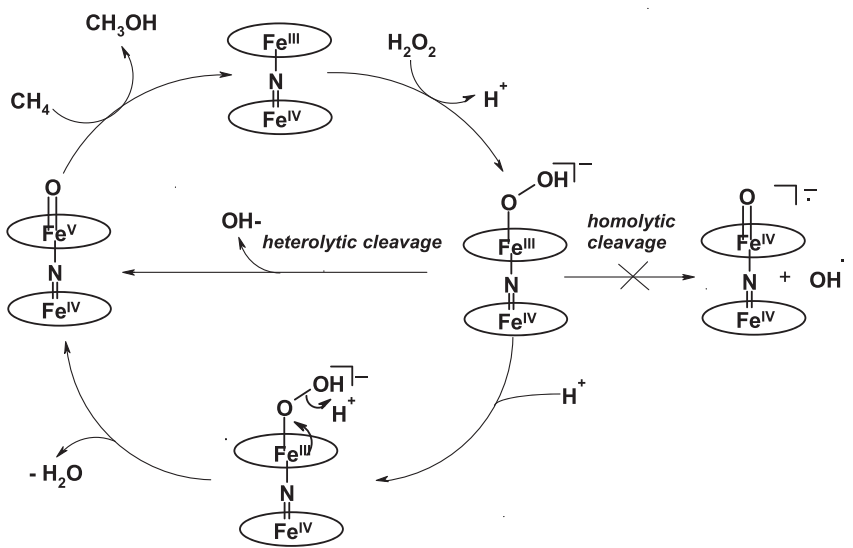

Figure 4. Proposed mechanism of the generation of the active species and the oxidation of methane.

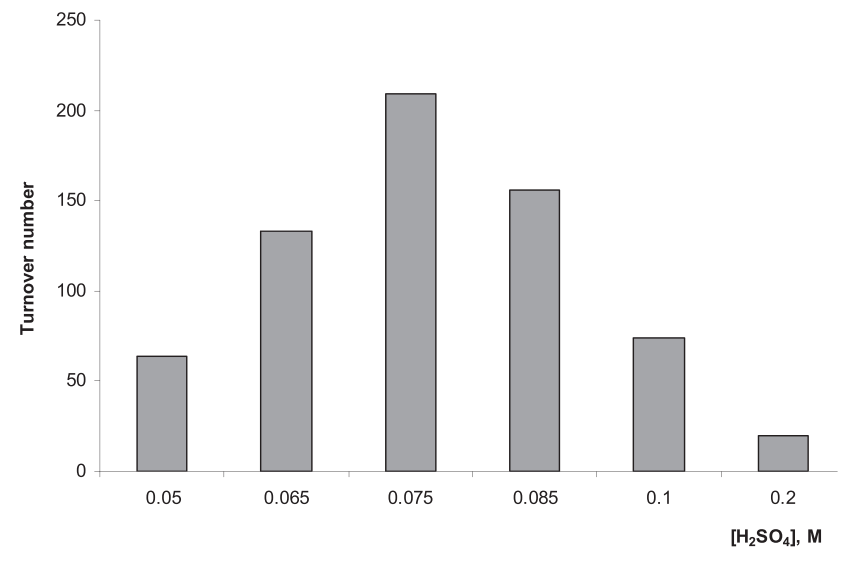

Figure 5. Dependence of the turnover numbers of methane oxidation on the $\mathrm{H}_{2} \mathrm{SO}_{4}$ concentration. Conditions: $2 \mathrm{ml}$ of water, methane - 32 bars, $0.925 \mu \mathrm{mol}$ of supported catalyst (18.5 $\mu \mathrm{mol} / \mathrm{g}), 678 \mu \mathrm{mol}$ of $\mathrm{H}_{2} \mathrm{O}_{2}$, reaction time $-20 \mathrm{~h}$.

Table 2. Oxidation of methane and ethylene by $\mathrm{H}_{2} \mathrm{O}_{2}$ catalyzed by supported $\left(\mathrm{FePc}^{t} \mathrm{Bu}_{4}\right)_{2} \mathrm{~N}$ complex.

\begin{tabular}{cccccc}
\hline Substrate & Solvent & {$\left[\mathrm{CH}_{2} \mathrm{O}\right], \mathrm{mmol}$} & {$[\mathrm{HCOOH}], \mathrm{mmol}$} & $\mathrm{TON}$ & Yield on $\mathrm{H}_{2} \mathrm{O}_{2}, \%$ \\
\hline $\mathrm{CH}_{4}$ & $\mathrm{H}_{2} \mathrm{O}$ & 1.5 & 10.5 & $26^{\mathrm{a}}$ & $\sim 5$ \\
$\mathrm{CH}_{4}$ & $0.075 \mathrm{M} \mathrm{H}_{2} \mathrm{SO}_{4}$ & 1.8 & 107 & $223^{\mathrm{a}}$ & 92 \\
$\mathrm{CH}_{2}=\mathrm{CH}_{2}$ & $\mathrm{H}_{2} \mathrm{O}$ & 14.3 & 86.3 & $115^{\mathrm{b}}$ & 51 \\
$\mathrm{CH}_{2}=\mathrm{CH}_{2}$ & $0.1 \mathrm{M} \mathrm{H}_{2} \mathrm{SO}_{4}$ & 17.9 & 107.6 & $143.5^{\mathrm{b}}$ & 69 \\
\hline
\end{tabular}

Experimental conditions: $2 \mathrm{ml}$ of solvent 32 bars of substrate, $0.925 \mu \mathrm{mol} \mathrm{supp}$. cat $(18.5 \mu \mathrm{mol} / \mathrm{g}), 678 \mu \mathrm{mol} \mathrm{H}_{2} \mathrm{O}_{2}, 60{ }^{\circ} \mathrm{C}$, reaction time $20 \mathrm{~h}$.

${ }^{a}$ TON calculated as $\left[\left(\mathrm{mol} \mathrm{CH}_{2} \mathrm{O}\right) \times 2+(\mathrm{mol} \mathrm{HCOOH}) \times 3\right] / \mathrm{mol}$ catalyst.

${ }^{b} \mathrm{TON}$ calculated as $\left[\left(\mathrm{mol} \mathrm{CH}_{2} \mathrm{O}\right) / 2+(\mathrm{mol} \mathrm{HCOOH}) / 2\right] / \mathrm{mol}$ catalyst.

a strong increase of the catalytic activity was observed (Figure 5).

The maximal catalytic activity was attained in $0.075 \mathrm{M}$ $\mathrm{H}_{2} \mathrm{SO}_{4}$. Under these conditions catalyst showed a remarkable performance: $223 \mathrm{CH}_{4}$ molecules were oxidized by each catalytic site. The yield of $\mathrm{HCOOH}$ on $\mathrm{H}_{2} \mathrm{O}_{2}$ was also high - $92 \%$ (Table 2). Oxidation of ethylene furnished the same oxidation products with high turnover numbers.
Evidently, the $\mathbf{1}-\mathrm{H}_{2} \mathrm{O}_{2}$ system can be used for the oxidation of other alkanes exemplified by the catalytic oxidation of propane in pure water. It should be noted, that solubility and concentration of propane in $\mathrm{H}_{2} \mathrm{O}$ is lower than those of methane and a lower propane pressure (20 bars) can be applied. Even under these conditions oxidation of propane was quite efficient. The GC-MS analysis of the final reaction mixture indicated the presence of propan-1-ol, propan-2-ol, 
propionaldehyde, acetone and propionic, acetic and formic acids:

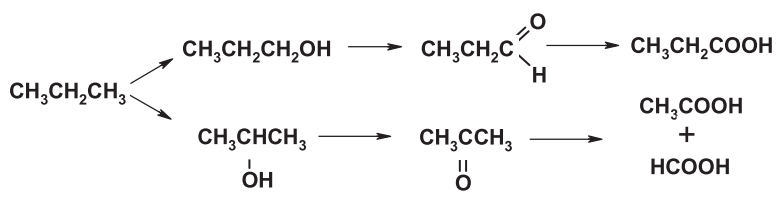

The formation of several products was expected since alcohols, the primary reaction products, are more easily oxidized than propane. This was confirmed using acetone as a substrate. The acetone was oxidized under these conditions with $84 \%$ conversion to form formic and acetic acids as major products.

\section{Oxidation of Benzene}

The scope of $\mu$-nitrido bridged diiron phthalocyanine was further investigated in the oxidation of benzene. ${ }^{[35]}$ This study has provided a valuable mechanistic information on the mechanism of the activation of $\mathrm{H}_{2} \mathrm{O}_{2}$ and properties of the active species involved in the oxidation. The main oxidation product was phenol obtained with TON of 66 at $60^{\circ} \mathrm{C}$ (Table 3 ).

Table 3. Oxidation of benzene catalyzed by $\left(\mathrm{FePc}^{t} \mathrm{Bu}_{4}\right)_{2} \mathrm{~N}$.

\begin{tabular}{ccccc}
\hline$[\mathrm{PhH}], \mathrm{M}$ & $\mathrm{T},{ }^{\circ} \mathrm{C}$ & Time, $\mathrm{h}$ & Conversion, $\%$ & $\mathrm{TON}_{\mathrm{PhOH}}$ \\
\hline 0.1 & 20 & 48 & 14 & 11 \\
0.1 & 40 & 20 & 20 & 12 \\
1 & 40 & 20 & n.d. & 28 \\
5.57 & 60 & 24 & n.d. & 66 \\
$11.14^{\text {a }}$ & 60 & 4 & n.d. & 32 \\
\hline
\end{tabular}

Conditions: $\left[\left(\mathrm{FePc}^{t} \mathrm{Bu}_{4}\right)_{2} \mathrm{~N}\right]=2.4 \cdot 10^{-4} \mathrm{M},\left[\mathrm{H}_{2} \mathrm{O}_{2}\right]=0.22 \mathrm{M}$ in $2 \mathrm{ml}$ $\mathrm{MeCN}$;

n.d. - not determined; ${ }^{a}$ neat $\mathrm{PhH}$.

In addition, other products were identified by GC-MS method. Small amount of $p$-benzoquinone was obtained from further oxidation of phenol. Most importantly, benzene oxide was initially identified by analysis of mass spectra of products obtained from $\mathrm{C}_{6} \mathrm{H}_{6}$ and $\mathrm{C}_{6} \mathrm{D}_{6} \cdot{ }^{[35]}$ To confirm this conclusion, benzene oxide was prepared independently according to literature protocol. ${ }^{[36,37]}$ The retention time and the mass spectrum of the authentic benzene oxide were the same as those of the product of benzene oxidation by $\left(\mathrm{FePc}^{t} \mathrm{Bu}_{4}\right)_{2} \mathrm{~N}-\mathrm{H}_{2} \mathrm{O}_{2}$ system. The formation of benzene oxide is especially important from mechanistic point of view. The initial formation of benzene oxide during oxidation of benzene to phenol was previously observed for cytochromes P-450 and toluene monooxygenases. The catalytic activity of these enzymes is associated with involvement of high-valent iron oxo species. Consequently, the formation of benzene oxide in the $\mathbf{1}-\mathrm{H}_{2} \mathrm{O}_{2}$ system is also compatible with our mechanistic proposal. The formation of benzene oxide in biological oxidation is usually accompanied by NIH shft which is a migration of the substituent from the site of hydroxylation to adjacent carbon atom. To check the occurrence of this phenomenon in our catalytic system we have introduced 1,3,5-trideuterobenzene as novel mechanistic probe for the detection of NIH shift. The use of this probe is based on the analysis of isotopic composition of $p$-benzoquinone as shown in ref. 35. When no NIH shift occurs only $p$-benzoquinone$d_{2}$ should be formed. The product obtained in the oxidation of 1,3,5-trideuterobenzene by $\left(\mathrm{FePc}^{t} \mathrm{Bu}_{4}\right)_{2} \mathrm{~N}-\mathrm{H}_{2} \mathrm{O}_{2}$ contained $75 \%$ of $p$-benzoquinone- $d_{2}, 19 \%$ of $p$-benzoquinone- $d_{3}$ and $6 \%$ of $p$-benzoquinone- $d_{1}$ thus indicating NIH shift which is compatible with the involvement of high-valent diiron oxospecies.

\section{Oxidation of Alkylaromatic Compounds}

In order to enlarge the choice of $\mu$-nitrido diiron phthalocyanine complexes and to check the influence of the structure on the catalytic properties we have prepared a series of complexes $\mathbf{2 a - 2 f}$ with electron-withdrawing $\mathrm{SO}_{2} \mathrm{R}(\mathrm{R}=$ alkyl, Figure 1$) .{ }^{[29-30]}$ The catalytic potential of these complexes was evaluated in aromatic oxidation using ${ }^{t} \mathrm{BuOOH}$ as oxidant. ${ }^{t} \mathrm{BuOOH}$ is widely used as the oxidant in combination with different transition metal catalysts. ${ }^{[38,39]}$ Alkyl aromatic compounds can be oxidized either at benzylic positions or in the aromatic ring. Catalytic systems capable of selectively oxidizing either only benzylic or only aromatic sites are highly desirable. However, this task is difficult to achieve. For example, toluene was oxidized by iron(II) complexes bearing hexa-, penta- or tetra-azadentate ligands $-\mathrm{H}_{2} \mathrm{O}_{2}$ system to mixture of isomeric cresols, benzyl alcohol and benzaldehyde. ${ }^{[40]}$ Oxidation of toluene performed by metalloporphyrin systems has often resulted in the mixture of products of benzylic and aromatic oxidation. ${ }^{[41]}$

In order to evaluate the reactivity of $\mu$-nitrido bridged diiron complexes toward oxidation of aliphatic $\mathrm{C}-\mathrm{H}$ vs.

Table 4. Oxidation of toluene by ${ }^{t} \mathrm{BuOOH}$ catalyzed by $\mathbf{1}, \mathbf{2 c}, \mathbf{2 d}$.

\begin{tabular}{|c|c|c|c|c|c|}
\hline Catalyst & $\mathrm{T},{ }^{\circ} \mathrm{C}$ & TON & $\mathrm{PhCH}_{2} \mathrm{OH}, \%$ & $\mathrm{PhCHO} \%$ & $\mathrm{PhCOOH}, \%$ \\
\hline \multirow{3}{*}{1} & 20 & 73 & 12 & 51 & 37 \\
\hline & 40 & 99 & 12 & 49 & 39 \\
\hline & 60 & 137 & 16 & 47 & 37 \\
\hline \multirow{3}{*}{$2 c$} & 20 & 92 & 6 & 21 & 73 \\
\hline & 40 & 197 & 5 & 12 & 83 \\
\hline & 60 & 167 & 6 & 13 & 81 \\
\hline \multirow[t]{2}{*}{$2 d$} & 40 & 86 & 7 & 16 & 77 \\
\hline & 60 & 115 & 7 & 16 & 77 \\
\hline
\end{tabular}

Reaction conditions: [catalyst] $=1 \mathrm{mM},\left[{ }^{t} \mathrm{BuOOH}\right]=206 \mathrm{mM}$ in $1 \mathrm{ml}$ of toluene, reaction time $24 \mathrm{~h}$. 
aromatic oxidation we have studied the oxidation of toluene and $p$-xylene by ${ }^{t} \mathrm{BuOOH} .{ }^{[29]}$ The oxidations were carried out without solvent, in $1 \mathrm{ml}$ of neat substrate. Avoiding the use of solvent is important advantage from the environmental and industrial points of view. The concentrations of catalyst and oxidant were $1 \mathrm{mM}$ and $206 \mathrm{mM}$, respectively. Benzylic alcohol, benzaldehyde and benzoic acid were the main products of oxidation of toluene. Table 4 shows the comparison of the results obtained in the presence of the complexes 1, 2c, 2 d.

Only traces of products of aromatic oxidation, p-cresol and 2-methyl-1,4-benzoquinone, were detected by GC-MS. Thus, the catalytic system demonstrates a strong preference for the oxidation of aliphatic $\mathrm{C}-\mathrm{H}$ bonds compared with aromatic oxidation. Notably, the selectivity of the oxidation of the methyl group depends on the catalyst structure. The catalysts $\mathbf{2 c}$ and $\mathbf{2 d}$ provided mainly benzoic acid with selectivity up to $83 \%$. In turn, 1 favours the formation of benzaldehyde. These catalysts showed TON up to 590 in the oxidation of $p$-xylene, $p$-toluic being the principal product. ${ }^{[29]}$

\section{Hydroacylation of Olefins as an Example of the Efficient $C-C$ Bond Formation}

Recently we have discovered a novel reactivity of $\mu$-nitrido-bis[tetra(tert-butyl)phthalocyaninatoiron] which can also be used as an efficient catalyst for C-C forming reactions. ${ }^{[42]}$ This finding significantly increases the scope of application of these emerging binuclear catalysts. The complex 1 catalyzed the addition of acetaldehyde to unactivated cyclic or linear alkenes under inert atmosphere using low catalyst loading $(0.01 \mathrm{~mol} \%)$ in the absence of organic solvent. In contrast to traditional oxidations involving ${ }^{t} \mathrm{BuOOH}$ in the presence of iron complexes to form the products of allylic oxidation, the $\mathbf{1}-{ }^{t} \mathrm{BuOOH}$ system was very efficient in the hydroacylation of olefins:<smiles>[X]C1C=C[C+](C)CCC1</smiles>

Importantly, the presence of $\left(\mathrm{FePc}^{t} \mathrm{Bu}_{4}\right)_{2} \mathrm{~N}$ is essential for the hydroacylation reactivity. When $\mathrm{FeSO}_{4} \cdot 7 \mathrm{H}_{2} \mathrm{O}$ or mononuclear iron tetra-tert-butylphthalocyanine were used instead of $\left(\mathrm{FePc}^{t} \mathrm{Bu}_{4}\right)_{2} \mathrm{~N}$ a product composition typical for usual radical oxidation with no formation of addition products was obtained. Optimization of the reaction conditions allowed achieving a high selectivity to hydroacylation products. The scope of $\left(\mathrm{FePc}^{t} \mathrm{Bu}_{4}\right)_{2} \mathrm{~N}-{ }^{t} \mathrm{BuOOH}$ system was evaluated in the functionalization of various olefins including linear substrates and substrates bearing functional groups (Table 5). ${ }^{[42]}$

The catalytic system was competent for hydroacylation of both cyclic and linear alkenes. In the case of octene-1 and 2-cyclohexen-1-one only the formation of the antiMarkovnikov product was observed. Using allylbenzene and 2-propen-1-ol, anti-Markovnikov and Markovnikov products were obtained in 95/5 and 83/17 ratios, respectively. This method can also be used with olefins containing easily oxidizable positions like in allylbenzene, 2-allylphenol and 2-cyclohexen-1-one. In all cases neither benzylic nor allylic oxidation products were detected. No oxidation of allylphenol to corresponding quinone was observed. Olefins containing a readily oxidizable hydroxyl group can also be hydroacylated without the need of any protecting group as was evidenced in the case of allyl alcohol. Very high turnover numbers for formation of methyl ketones have been achieved (3600 -

Table 5. Hydroacylation of different olefins catalyzed by $\left(\mathrm{FePc}^{t} \mathrm{Bu}_{4}\right)_{2} \mathrm{~N}$.

Entry

\footnotetext{
${ }^{a}$ Reaction conditions: olefin $(10 \mathrm{mmol})$, acetaldehyde $(100 \mathrm{mmol})$, catalyst $(1 \mu \mathrm{mol}, 0.01 \mathrm{~mol} \%), 60^{\circ} \mathrm{C}, 24 \mathrm{~h} .{ }^{\mathrm{b}}$ Yields were determined by GC. ${ }^{\mathrm{c}} 0.1 \mathrm{~mol} \%$ catalyst loading. ${ }^{\mathrm{d}}$ Isolated mixture consisting of a $95 / 5$ mixture of anti-Markovnikov and Markoknikov isomers. ${ }^{\mathrm{e}}$ Isolated mixture consisting of a $83 / 17$ mixture the isomers.
} 
5700). Unreacted $\mathrm{CH}_{3} \mathrm{CHO}$ left in the reaction mixture after reaction can easily be recycled and reused.

\section{Conclusion}

In summary, we have discovered remarkable catalytic properties of $\mu$-nitrido bridged diiron phthalocyanines. Available to date spectroscopic and mechanistic data indicate a very rich chemistry of this new type of oxidation catalysts. In particular, the $\mathrm{PcFe}-\mathrm{N}=\mathrm{FePc}$ scaffold is able to stabilize high-valent iron oxidation states. ${ }^{[43]}$ This complex activates $\mathrm{H}_{2} \mathrm{O}_{2}$ via heterolytic cleavage of $\mathrm{O}-\mathrm{O}$ bond to form a highvalent diiron oxo species with unusual reactivity. This species is able to oxidize methane and benzene under very mild conditions. Nevertheless, many further efforts are necessary to get a deep mechanistic insights in order to understand the origin of these remarkable catalytic properties. Both experimental advanced spectroscopic ${ }^{[44]}$ and theoretical ${ }^{[45]}$ approaches will contribute to achieving this goal.

Cleanness of this system coupled with availability of the phthalocyanines suggests a possible application potential of this approach. In addition, this system has a great potential for further development by the modification of the structure (various metals and ligands can be used) that would lead to the improvement of the catalytic performance and to the tailored catalysts for the oxidation of compounds of different nature and many applications can be envisaged.

Acknowledgements. We thank our co-workers for their valuable contributions to the development of this project. Their names are given in the references. Our special thanks go to Dr. Pavel Afanasiev for collaboration and many fruitful discussions. This research was supported by Agence National de Recherche (ANR, France, grant ANR-08-BLANC-0183-01).

\section{References}

1. Goedken V.L., Ercolani C. J. Chem. Soc. Chem. Commun. 1984, 378-379.

2. Summerville D.A., Cohen I.A. J. Am. Chem. Soc. 1976, 98, 1747-1752.

3. Bottomley L.A., Gorce J.-N., Goedken V.L., Ercolani C. Inorg. Chem. 1985, 24, 3733-3737.

4. Ercolani C., Gardini M., Pennesi G., Rossi G., Russo U. Inorg. Chem. 1988, 27, 422-424.

5. Rossi G., Gardini M., Pennesi C., Ercolani C., Goedken V. J. Chem. Soc. Dalton Trans. 1989, 193-195.

6. Ercolani C., Hewage S., Heucher R., Rossi G. Inorg. Chem. 1993, 32, 2975-2977.

7. Ercolani C., Jubb J., Pennesi G., Russo U., Trigiane G. Inorg. Chem. 1995, 34, 2535-2541.

8. Donzello M.P., Ercolani C., Kadish K.M., Ou Z., Russo U. Inorg Chem. 1998, 37, 3682-3688.

9. Donzello M.P., Ercolani C., Russo U., Chiesi-Villa, A., Rizzoli C. Inorg Chem. 2001, 40, 2963-2967.

10. Kennedy B.J., Murray K.S., Homborg H., Kalz W. Inorg. Chim. Acta 1987, 134, 19-21.

11. Moubaraki P.B., Benlian D., Baldy A., Pierrot M. Acta Cryst. 1989, C45, 393-394.

12. Stuzhin P.A., Hamdush M., Homborg H. Mendeleev Commun. 1997, 7, 196-198
13. Stuzhin P.A., Latos-Grażyński L., Jezierski A. Transition Met. Chem. 1989, 14, 341-346.

14. Kudrik E.V., Afanasiev P., Sorokin A.B. Macroheterocycles 2010, 3, 19-22.

15. Jüstel T., Müller M., Weyhermüller T., Kressl C., Bill E., Hildebrandt P., Lenglen M., Grodzicki M., Trautwein A.X., Nuber B., Wieghardt K. Chem. Eur. J. 1999, 5, 793-810.

16. Floris B., Donzello M.P., Ercolani C. Single-Atom Bridged Dinuclear Metal Complexes with Emphasis on Phthalocyanine Systems. In: The Porphyrin Handbook (Kadish K.M., Smith K.M., Guilard R., Eds.). San Diego: Elsevier Science, 2003, Vol. 18, pp. 1-62.

17. Kudrik E.V., Afanasiev P., Bouchu D., Millet J.-M.M., Sorokin A.B. J. Porphyrins Phthalocyanines 2008, 12, 1078-1089.

18. Sorokin A.B., Mangematin S., Pergrale C. J. Mol. Catal. A 2002, 182-183, 267-281.

19. Pergrale C., Sorokin A.B. C. R. Chimie 2000, 3, 803-810.

20. Sorokin A.B., Tuel A. Catal. Today 2000, 57, 45-59.

21. Zalomaeva O.V., Ivanchikova I.D., Kholdeeva O.A., Sorokin A.B. New J. Chem. 2009, 33, 1031-1037.

22. Zalomaeva O.V., Sorokin A.B., Kholdeeva O.A. Green Chem. 2010, 12, 1076-1082.

23. Gonzalez L.-M., Villa de P.A.L., Montes de C.C., Sorokin A.B. Tetrahedron Lett. 2007, 47, 6465-6468.

24. Neu H.M., Zhdankin V.V., Nemykin V.N. Tetrahedron Lett. 2010, 51, 6545-6548.

25. Geraskin I.M., Pavlova O., Neu H.M., Yusupov M.S., Nemykin V.N., Zhdankin V.V. Adv. Synth. Cat. 2009, 351, 733-737.

26. Neu H.M., Yusupov M.S., Zhdankin V.V., Nemykin V.N. $A d v$. Synth. Cat. 2009, 351, 3168-3174.

27. Geraskin I.M., Luedtke M.W., Neu H.M., Nemykin V.N., Zhdankin V.V. Tetrahedron Lett. 2008, 49, 7410-7412.

28. Sorokin A.B., Kudrik E.V., Bouchu D. Chem. Comm. 2008, 2562-2564.

29. Isci Ü., Afanasiev P., Millet J.M.M., Kudrik E.V., Ahsen V., Sorokin A.B. Dalton Trans. 2009, 7410-7420.

30. Isci Ü., Dumoulin F., Ahsen V., Sorokin A.B. J. Porphyrins Phthalocyanines 2010, 14, 324-334.

31. Kudrik E.V., Afanasiev P., Bouchu D., Sorokin A.B. J. Porphyrins Phthalocyanines 2011, DOI: 10.1142/ S1088424611003471.

32. Sorokin A.B., Kudrik E.V. Catal. Today 2011, 159, 37-46.

33. Afanasiev P., Kudrik E.V., Millet J.M.M., Bouchu D., Sorokin A.B. Dalton Trans. 2011, 40, 701-710.

34. Sorokin A.B., Kudrik E.V., Alvarez L.X., Afanasiev P., Millet J.M.M., Bouchu D. Catal. Today 2010, 157, 149-154.

35. Kudrik E.V., Sorokin A.B. Chem. Eur. J. 2008, 14, 7123-7126.

36. Rastetter W. H. J. Am. Chem. Soc. 1976, 98, 6350-6353.

37. Davies S.G., Polywka M.E.C., Thomas S.E. J. Chem. Soc. Perkin Trans. 1 1986, 1277-1282.

38. Muzart J. Chem. Rev. 1992, 92, 113-140.

39. Khenkin A.M., Neumann R. J. Am. Chem. Soc. 2004, 126, 6356-6362.

40. Balland V., Matheieu D., Pons-Y-Moll N., Bartoli J.F., Banse F., Battioni P., Girerd J.-J., Mansuy D. J. Mol. Catal. A: Chem. 2004, 215, 81-87.

41. Mathieu D., Bartoli J.F., Battioni P., Mansuy D. Tetrahedron 2004, 60, 3855-3862.

42. Alvarez L.X., Kudrik E.V., Sorokin A.B. Chem. Eur. J. 2011, 17, 9298-9301.

43. Afanasiev P., Bouchu D., Kudrik E.V., Millet J.-M. M., Sorokin A.B. Dalton Trans. 2009, 9828-9836.

44. Kudrik E.V., Safonova O., Glatzel P., Grattage J., Alvarez L.X., Sorokin A.B., Afanasiev P. Submitted.

45. Silaghi-Dumitresku R., Makarov S.V., Uta M.-M., Dereven'kov I.A., Stuzhin P.A. New J. Chem. 2011, 35, 1140-1145. 